\title{
Growth and development of very low birthweight infants recovering from bronchopulmonary dysplasia
}

\author{
V Y H YU, A A ORGILL, S B LIM, B BAJUK, AND J ASTBURY \\ Department of Paediatrics, Queen Victoria Medical Centre, Melbourne
}

SUMMARY Twenty four infants with birthweights $\leqslant 1500 \mathrm{~g}$ had bronchopulmonary dysplasia (BPD). Four died in the neonatal period and four in the postneonatal period-one had been discharged and was aged one year. Sixteen (67\%) survived long term and were followed up until they were two years old. Common medical conditions included respiratory illnesses in $14(88 \%)$ children and otitis media in $8(50 \%)$. Eleven $(69 \%)$ required hospital admission for an average of 5 times; total days in hospital averaged 27 days. The most common reasons for admission were bronchiolitis and bronchopneumonia. At two years $37 \%$ were below the 10th centile for weight, as were $25 \%$ for height: head circumferences were normal. Two children had cerebral palsy, two had developmental delay, two had multiple disabilities, and one had sensorineural deafness. Of the 24 BPD infants, $8(33 \%)$ died, $7(29 \%)$ survived with a disability (severe in one), and $9(38 \%)$ had a normal neurodevelopmental outcome. From the available perinatal data it was not possible to predict late disabilities in BPD survivors.

Bronchopulmonary dysplasia (BPD) is associated with a high mortality in very low birthweight (VLBW, $\leqslant 1500 \mathrm{~g}$ ) infants, and a prolonged initial hospital stay in survivors. Despite the importance of this complication, little has been published on the late outcome of children recovering from BPD. BPD survivors, birthweight ranging up to $2600 \mathrm{~g}$, were found to have $25-34 \%$ major disabilities. ${ }^{12}$ In a recent report $8(62 \%)$ of 13 VLBW survivors with BPD had a neurological deficit. ${ }^{3}$

We describe the physical growth, respiratory morbidity, and neurodevelopmental outcome of VLBW children with BPD, born over the four year period 1977-1980, and treated at this hospital. We also endeavour to identify perinatal risk factors that predicted disabilities in BPD survivors.

\section{Patients and methods}

Study population. The VLBW population of 375 infants admitted to this hospital during the study period has been reported. ${ }^{4}$ Twenty four $(6 \%)$ had BPD. The diagnosis of BPD was made in patients who fulfilled the following criteria:

(1) Developed clinical signs of chronic respiratory disease on assisted ventilation.

(2) Continued to manifest these clinical features for more than 28 days and needed supplementary oxygen for more than 28 days to maintain a $\mathrm{PaO}_{2}$ over $50 \mathrm{mmHg}$, in those who survived for this period of time.

(3) Chest radiograph showed irregular and linear strands of dense opacities in both lungs, alternating with areas of normal or increased lucency.

Four infants died during the neonatal period and 3 died in the postnatal period during the initial stay in hospital. All $17(71 \%)$ hospital survivors were prospectively enrolled in the Growth and Development Clinic.

Follow up. All long term survivors were assessed at two years of age, corrected for prematurity. At the clinic, a history of respiratory difficulties and hospital admissions was obtained, and a physical and neurological examination was completed. Their development was assessed according to the Bayley scales of infant development, which included a mental developmental index (MDI) and a psychomotor developmental index (PDI). Disability was defined as reported, ${ }^{5}$ and included cerebral palsy of any type or severity, developmental delay (MDI more than 2 SD below the mean), blindness, and sensorineural deafness.

Statistical analysis. This was performed using the $\chi^{2}$ test with Yates's correction and the Student's $t$ test, where appropriate. 


\section{Results}

Late mortality. Of the 17 hospital survivors, one died at one year of age with bronchopneumonia, acute gastroenteritis, and Escherichia coli septicaemia. The long term survival rate was therefore $67 \%$. Results of this study were based on data from the 16 children assessed at two years' corrected age.

General health. During the first two years, notable respiratory illness was found in $14(88 \%)$ children. This included wheezing episodes in $12(75 \%)$ children, pneumonia in $7(44 \%)$, attacks of stridor and croup in four $(25 \%)$, and asthma in one child. In addition, $8(50 \%)$ children had otitis media, four $(25 \%)$ had gastroenteritis, and one child had viral meningitis and a subsequent febrile convulsion.

Consequent to the repeated ill health, only 10 $(63 \%)$ children were able to complete their schedule of triple vaccine and immunisation for poliomyelitis and measles. In addition, one child completed the schedule without immunisation for measles and 3 did not complete their triple vaccination. Two children did not have any immunisation.

Five $(31 \%)$ children had feeding problems which included colic (4), gastrointestinal reflux (3), and vomiting (2). These occurred in both breast fed and formula fed children. Eleven children $(69 \%)$ were fed expressed breast milk before hospital discharge. The incidence of breastfeeding was $10(63 \%)$ at three months, five $(31 \%)$ at 6 months, and two $(13 \%)$ at 9 months. One child continued breastfeeding beyond one year of age.

Hospital admissions. Eleven children (69\%) needed hospital treatment during the two years-10 $(63 \%)$ in the first year, and $7(44 \%)$ in the second. The average number of admissions was five (range 1-13). The duration of stay ranged from 1-20 days per admission (mean 5 days), and the total number of days in hospital ranged from 2-86 (mean 27) days. Most hospital admissions were for respiratory illnesses (Table 1). One infant required a iracheostomy for subglottic stenosis. In addition, one infant was discharged on home oxygen therapy. Both these infants had to be admitted on five occasions for reassessment regarding weaning from treacheostomy and oxygen therapy, respectively.

Growth. All children except one were the appropriate weight for gestational age at birth. At 2 years of age, the mean weight was at the 10th percentile, the mean height was at the 10-25th percentile, and the mean head circumference was at the 50th percentile (Table 2). Four ( $25 \%$ ) children had a weight and length below the 3rd percentile, although their head circumference was close to the 50th percentile.
Table 1 Reasons for repeat admissions to hospital

\begin{tabular}{lll}
\hline & $\begin{array}{l}\text { Number of } \\
\text { children }\end{array}$ & $\begin{array}{l}\text { Number of } \\
\text { admissions }\end{array}$ \\
\hline Bronchiolitis/asthma & 2 & 16 \\
Bronchopneumonia & 2 & 5 \\
Aspiration pneumonia & 2 & 3 \\
Shepherd's tube insertion & 2 & 2 \\
Weaning from tracheostomy & 1 & 5 \\
Transcutanous oxygen monitoring & 1 & 5 \\
Viral meningitis & 1 & 1 \\
Febrile convulsion & 1 & 1 \\
Feeding problem & 1 & 1 \\
Social problem & 1 & 1 \\
Miscellaneous surgery & & \\
$\quad$ Congenital hip dislocation & 1 & 8 \\
Inguinal hernia repair & 1 & 1 \\
Toe operation & 1 & 1 \\
\hline
\end{tabular}

Table 2 Growth centiles at two years of age

\begin{tabular}{lcll}
\hline Percentiles & $\begin{array}{l}\text { Weight } \\
\text { No (\%) }\end{array}$ & $\begin{array}{l}\text { Height } \\
\text { No (\%) }\end{array}$ & $\begin{array}{l}\text { Head } \\
\text { circumference } \\
\text { No (\%) }\end{array}$ \\
\hline Over 90th & $0(0)$ & $0(0)$ & $0(0)$ \\
50th-90th & $0(0)$ & $3(19)$ & $8(50)$ \\
10th-49th & $10(63)$ & $9(56)$ & $7(44)$ \\
Below 10th & $6(37)$ & $4(25)$ & $1(6)$ \\
\hline
\end{tabular}

Neurodevelopmental outcome. Two children had right hemiplegia, and one had monoplegia affecting the right arm (Table 3, cases 1-3). In addition to one child with cerebral palsy whose MDI score was more than 2SD below the mean, two children (cases 4 and 5) had an isolated MDI of 52 and 50 respectively. The score for the MDI was mean (SD) 88 (25) and the score for the PDI was mean (SD) 81 (13). Two children (cases 6 and 7) had sensorineural deafness requiring a hearing aid, and one of these, with bilateral retrolental fibroplasia, was also blind.

Eight (33\%) of the 24 infants in this series died, $7(29 \%)$ survived with a disability, and $9(38 \%)$ had a normal neurodevelopmental outcome. Although 7 $(44 \%)$ of the long term survivors had a disability as defined above, the cerebral palsy interfered only to a moderate extent with normal daily function, and in only one $(6 \%)$ survivor was the disability severe (case 7).

Perinatal factors. The early hospital course of the 7 BPD survivors with disabilities identified at 2 years of age was compared with that of 9 survivors without disabilities. The comparison included gestational age, birthweight, sex, Apgar scores, need for intubation or bicarbonate treatment at birth, arterial $\mathrm{pH}$ and blood gases on hospital admission, duration of oxygen and ventilatory treatment, duration of hospital stay, and the mean daily caloric 
Table 3 Bronchopulmonary dysplasia survivors with handicaps

\begin{tabular}{|c|c|c|c|c|c|c|c|c|}
\hline \multirow[t]{2}{*}{ Case No } & \multirow{2}{*}{$\begin{array}{l}\text { Gestational age } \\
\text { (weeks) }\end{array}$} & \multirow{2}{*}{$\begin{array}{l}\text { Birthweight } \\
(\mathrm{g})\end{array}$} & \multirow[t]{2}{*}{ Sex } & \multirow{2}{*}{$\begin{array}{l}\text { Cerebral } \\
\text { palsy }\end{array}$} & \multirow[t]{2}{*}{ Blindness } & \multirow{2}{*}{$\begin{array}{l}\text { Sensorineural } \\
\text { deafness }\end{array}$} & \multicolumn{2}{|c|}{ Bayley scores } \\
\hline & & & & & & & $M D I$ & $P D I$ \\
\hline $\begin{array}{l}1 \\
2 \\
3 \\
4 \\
5 \\
6 \\
7\end{array}$ & $\begin{array}{l}25 \\
26 \\
26 \\
27 \\
27 \\
27 \\
29\end{array}$ & $\begin{array}{r}730 \\
800 \\
880 \\
850 \\
1030 \\
1230 \\
1120\end{array}$ & $\begin{array}{l}\mathbf{F} \\
\mathbf{M} \\
\mathbf{F} \\
\mathbf{M} \\
\mathbf{M} \\
\mathbf{M} \\
\mathbf{M}\end{array}$ & $\begin{array}{l}\text { Hemiplegia } \\
\text { Hemiplegia } \\
\text { Monoplegia } \\
= \\
= \\
= \\
-\end{array}$ & $\begin{array}{l}= \\
= \\
= \\
\overline{-} \\
\text { Bilateral RLF }\end{array}$ & $\begin{array}{l}\overline{-} \\
\overline{-} \\
\bar{Z} \\
\begin{array}{c}\text { Present } \\
\text { Present }\end{array}\end{array}$ & $\begin{array}{r}<50 \\
87 \\
106 \\
50 \\
52 \\
85 \\
\text { NT }\end{array}$ & $\begin{array}{l}82 \\
78 \\
93 \\
85 \\
64 \\
71 \\
\text { NT }\end{array}$ \\
\hline
\end{tabular}

$\mathrm{NT}=$ not tested $; \mathrm{RLF}=$ retrolental fibroplasia $; \mathrm{MDI}=$ mental developmental index; PDI = psychomotor developmental index.

intake in the first four weeks after birth. No perinatal risk factor was found to influence outcome adversely. Those survivors with disabilities required a shorter period of assisted ventilation compared with the rest, suggesting that persistent respiratory failure was not a major contributing factor. In this study, infants with BPD who subsequently developed a disability would not have been identified from the perinatal data. The diagnosis of periventricular haemorrhage by cerebral ultrasonography was only available towards the end of the study.

\section{Discussion}

Advances in perinatal care have resulted not only in a reduction in the neonatal mortality rate, but also in an extension of the period during which the infant remains at risk of death. The reasons for these late deaths are directly related to complications of prematurity and intensive care. Some VLBW infants are kept alive with ventilatory support, parenteral nutrition, and other treatments, only to die eventually from as yet unpreventable or uncurable diseases. It has been reported that $14 \%$ of the deaths in VLBW infants occurred in the postneonatal period and $50 \%$ of the postneonatal deaths which occurred during the initial hospitalisation were caused by BPD. ${ }^{6}$ In the present study, three of the 7 hospital deaths in infants with BPD occurred in the postneonatal period. This pattern is in contrast with that for the overall VLBW population during the four year study period, when over half of the infants who died in hospital had done so by age 48 hours. ${ }^{4}$

The postdischarge death rate of infants treated in a neonatal intensive care unit was found to be 7 fold that of the general population. ${ }^{7}$ In VLBW survivors, sudden infant death syndrome (SIDS) is the predominant cause of death, ${ }^{8}$ and a recent study showed that the incidence of SIDS was 7 times greater in preterm infants with BPD compared with a control group without BPD. ${ }^{9}$ There was only one postdischarge infant death in this series, and the number of survivors was too small to reflect the increased vulnerability of children recovering from BPD that has been suggested in the published reports.

In this study the persistent respiratory morbidity and repeated hospital admissions during the first two years confirmed similar findings in other reports. ${ }^{1-3}$ Although progressive clinical improvement is expected, subtle functional disturbance of lung function and bronchial hyperactivity that may have life long consequences have been detected late into childhood. ${ }^{10}$ Growth failure may be related to a greater expenditure of energy and hypoxia, associated with the persistent respiratory distress, and from the emotional disruption or deprivation from being severely ill and from hospital admissions. The growth potential of these infants needs to be ascertained with further long term follow up.

The neurodevelopmental outcome in our VLBW survivors with BPD is relatively more favourable than that reported in the only comparable series. ${ }^{3}$ Nevertheless, the incidence of disability is higher than that in the overall VLBW population, in which at least $90 \%$ of the survivors are expected to function within the normal range. ${ }^{11}$ From the available perinatal data it was not possible to predict late disabilities in the BPD survivors, and therefore prevention of disabilities by selective treatment had no prospect of success. The finding that BPD in the VLBW infant remains a serious complication with short and long term consequences, emphasises the importance of research into its prevention or amelioration.

\section{References}

1 Northway WH, Jr. Observations on bronchopulmonary displasia. J Pediatr 1979;95:815-8.

2 Markestad T, Fitzhardinge PM. Growth and development in children recovering from bronchopulmonary dysplasia. J Pediatr 1981;98:597-602.

3 Vohr BR, Bell EF, Oh W. Infants with bronchopulmonary dysplasia. Am J Dis Child 1982;136:443-7.

$4 \mathrm{Yu}$ VYH, Zhao SM, Bajuk B. Results of intensive care for 375 very low birthweight infants. Aust Paediatr J $1982 ; 18$ : 188-92. 
5 Orgill AA, Astbury J, Bajuk B, Yu VYH. Early development of infants $1000 \mathrm{~g}$ or less at birth. Arch Dis Child $1982 ; 57: 823-7$.

6 Hack M, Merkatz IR, Jones PK, Fanaroff AA. Changing trends of neonatal and postneonatal deaths in very-lowbirth-weight infants. Am J Obstet Gynecol 1980;137: 797-800.

7 Sells CJ, Neff TE, Bennett FC, Robinson NM. Mortality in infants discharged from a neonatal intensive care unit. Am J Dis Child 1983;137:44-7.

8 Kitchen WH, Yu VYH, Lissenden JV, Bajuk B. Collaborative study of very-low-birthweight infants: techniques of perinatal care and mortality. Lancet 1982 ;i: 1454-7.

9 Werthammer J, Brown ER, Neff RK, Taeusch HW, Jr.
Sudden infant death syndrome in infants with bronchopulmonary dysplasia. Pediatrics 1982;69:301-4.

10 Smyth JA, Tabachnik E, Duncan WJ, Reilly BJ, Levison $\mathrm{H}$. Pulmonary function and bronchial hyperactivity in long-term survivors of bronchopulmonary dysplasia. Pediatrics $1981 ; 68: 336-40$.

11 Orgill AA, Astbury J, Bajuk B, Yu VYH. Early neurodevelopmental outcome of very low birthweight infants. Aust Paediatr J 1982;18:193-6.

Correspondence to V Y H Yu, Department of Paediatrics, Queen Victoria Medical Centre, 172 Lonsdale Street, Melbourne, Victoria 3000, Australia.

Received 18 June 1983
Fifty years ago

\section{Case of staphylococcal septicaemia in a girl of 10 years with orbital metastasis}

\section{A HAYES SMITH (Bradford)}

Dr Hayes Smith related an example of this condition due to Staphylococcus aureus, secondary to a furuncle on the forearm. Recovery ensued. The treatment comprised concentrated antitoxic anti- staphylococcal serum, intramuscular liver liquid and drainage of the orbit. . . . The practical uselessness of blood culture was stressed and attention was drawn to the early evidence of toxic collapse afforded by the difference between the rectal temperature and that of the dried axilla, a difference of $3^{\circ}$ suggesting a guarded prognosis and $5^{\circ}$ a very grave one.

Archives of Disease in Childhood 1933; 8: 363. (PRE)

(Hayes Smith was a general practitioner and assistant physician to Bradford Children's Hospital as well as being an ardent member of the Society of Individualists. Phillip Evans). 